This item was submitted to Loughborough's Research Repository by the author.

Items in Figshare are protected by copyright, with all rights reserved, unless otherwise indicated.

\title{
Finding the missing voices of Sport for Development and Peace (SDP): using a 'Participatory Social Interaction Research' methodology and anthropological perspectives within African developing countries
}

\section{PLEASE CITE THE PUBLISHED VERSION}

https://doi.org/10.1080/17430437.2016.1179732

\section{PUBLISHER}

(C) Taylor and Francis

\section{VERSION}

AM (Accepted Manuscript)

\section{PUBLISHER STATEMENT}

This work is made available according to the conditions of the Creative Commons Attribution-NonCommercialNoDerivatives 4.0 International (CC BY-NC-ND 4.0) licence. Full details of this licence are available at: https://creativecommons.org/licenses/by-nc-nd/4.0/

\section{LICENCE}

CC BY-NC-ND 4.0

\section{REPOSITORY RECORD}

Collison, Holly, and David Marchesseault. 2019. "Finding the Missing Voices of Sport for Development and Peace (SDP): Using a 'participatory Social Interaction Research' Methodology and Anthropological Perspectives Within African Developing Countries”. figshare. https://hdl.handle.net/2134/32631. 
DOI: 10.1080/17430437.2016.1179732

\section{Journal: Sport in Society}

Manuscript ID: 1179732

\section{File Correction Details}

Correction is made. No of Corrections: 10

Online Correction Link : http://tandfproof.sps.co.in:8080/oxe_tf_v3/index.php?

token=dApTWK8hLABofoBW_xR7OC9MyzDmB3_V1060utQYvjPC3ftc9br7ZQ

\section{Image Annotation Details}

No Details Found

\section{Attached File Details}

No Details Found

\section{List of Comments}

\begin{tabular}{|l|l|l|}
\hline S.No & Text & Comments \\
\hline 1 & authorOrAffiliationGroup & missing 't' on the end of David's surname \\
\hline
\end{tabular}

\section{Query Details}

1. Please provide missing city and country for affiliation ' $a$ '.

Loughborough University, Leicestershire, UK

2. Please provide missing department and city for affiliation 'b'.

Faculty of Kinesiology \& Physical Education.

Toronto

3. The reference 'Hayhurst et al., 2015' is cited in the text but is not listed in the references list. Please either delete in-text citation or provide full reference details following journal style [http://www.tandf.co.uk/journals/authors/style/reference/tf_ChicagoAD.pdf].

Hayhurst, L.M, Giles, AR and Radforth, W.M, 2015. 'I want to come here to prove them wrong': Using a post-colonial feminist participatory action research (PFPAR) approach to studying sport, gender and development programmes for urban indigenous young women. Sport in Society, 18 (8): 952-967.

4. The reference 'Olivier de Sardan, 2005' is cited in the text but is not listed in the references list. Please either delete in-text citation or provide full reference details following journal style [http://www.tandf.co.uk/journals/authors/style/reference/tf_ChicagoAD.pdf].

Olivier de Sardan, J.P. 2005. Anthropology and Development: Understanding Contemporary Social Change. London \& New York: Zed Books.

5. The reference 'Buetler, 2006' is cited in the text but is not listed in the references list. Please either delete intext citation or provide full reference details following journal style 
[http://www.tandf.co.uk/journals/authors/style/reference/tf_ChicagoAD.pdf].

This should read: (Beutler 2008)

Beutler, I. 2008. Sport senving development and peace: Achieving the goals of the United Nations through Sport. Sport in Society, 11 (4): $359-369$.

6. The reference 'Hobberman, 2011' is cited in the text but is not listed in the references list. Please either delete in-text citation or provide full reference details following journal style

[http://www.tandf.co.uk/journals/authors/style/reference/tf_ChicagoAD.pdf].

Hoberman, J. 2011. The Myth of Sport as a Peace-Promoting Political Force. Review of International Affairs, 31 (1): 17-29.

7. Please provide the names of all relevant authors (as per journal style, if there are four to ten authors, please provide all author names. If there are more than ten authors, just the first seven names are required, followed by et al.)

Caddick, N., Smith, B., and Phoenix, C. 2015.

8. The reference 'Choudry (2013)' is listed in the references list but is not cited in the text. Please either cite the reference or remove it from the references list.

Please delete reference

9. Please provide missing city for the "Coalter, 2009" references list entry.

Resolved in text

10. The CrossRef database (www.crossref.org/) has been used to validate the references. Mismatches between the original manuscript and CrossRef are tracked in red font. Please provide a revision if the change is incorrect. Do not comment on correct changes.

Unsure of what is being asked here. The reference is correct.

11. The reference 'Comstock (1993)' is listed in the references list but is not cited in the text. Please either cite the reference or remove it from the references list.

Please delete reference

12. The reference 'Cutt (1982)' is listed in the references list but is not cited in the text. Please either cite the reference or remove it from the references list.

Please delete reference

13. Please provide the names of all relevant authors (as per journal style, if there are four to ten authors, please provide all author names. If there are more than ten authors, just the first seven names are required, followed by et al.)

Please delete reference

14. The reference 'Fawcett (1996)' is listed in the references list but is not cited in the text. Please either cite the reference or remove it from the references list.

Please delete reference

15. Please provide missing volume and page numbers for the "Forde 2013" references list entry.

$0(0): 1-16$

16. The reference 'Frisby (2005)' is listed in the references list but is not cited in the text. Please either cite the reference or remove it from the references list.

Please remove from the reference list

17. Please provide missing city for the "Game and Metcalfe, 1996" references list entry.

London, Thousand Oaks, New Delhi: Sage

18. The reference 'Kay (2009)' is listed in the references list but is not cited in the text. Please either cite the reference or remove it from the references list.

Resolved in text 
19. The reference 'Maanen (1988)' is listed in the references list but is not cited in the text. Please either cite the reference or remove it from the references list.

\section{Resolved in text}

20. Please provide missing page numbers for the "Richards 1997" references list entry.

$141-158$

21. The reference 'Tsuda (2014)' is listed in the references list but is not cited in the text. Please either cite the reference or remove it from the references list.

Please delete reference

22. Please provide missing city for the "Weisgrau, 1997" references list entry.

Resolved in text

23. Please provide missing city for the "Wilkinson, 2004" references list entry.

Resolved in text

24. Please provide missing publisher for the "Wilkinson, 2004" references list entry.

Resolved in text 


\title{
Finding the missing voices of Sport for Development and Peace (SDP): using a 'Participatory Social Interaction Research' methodology and anthropological perspectives within African developing countries
}

Running heads:

Sport in Society

H. Collison and D. Marchesseaul missing 't' on the end of David's surname

Collison Holly a, *

Marchesseault David b

$A Q 1$

Sport for Development and Peace in International Contexts, Loughborough University

AQ2

Toronto University, Canada

*Corresponding author. Email: H.Collison@lboro.ac.uk

(C) 2016 Informa UK Limited, trading as Taylor \& Francis Group

\begin{abstract}
Whilst the SDP sector has in recent years continued to gain momentum, academic enquiry has largely continued to question its place within development agendas from the outside looking in, examining SDP at the operational and policy levels using methods that advocate the formal guises of research. Through extensive fieldwork experiences in Rwanda and Liberia, the authors propose a form of participatory research methodology for the purpose of empowerment, cultural understanding and insight beyond policy, practice and evaluation. Participatory social interaction research (PSIR) methodology is thus introduced and developed as an approach that looks beyond interventions, deconstructs SDP rhetoric, conceptualizes according to culturally specific contexts and allows narratives and qualitative data to drive theorization and academic discussion. We believe that an embodied, thorough and thoughtful PSIR methodology locates not only diversity within an ill-defined 'African' context, but empowers local voices to construct detailed accounts of culture within and outside of SDP.
\end{abstract}

\section{Introduction}

Sport and physical activity has been used as an ad hoc way of reaching development-related objectives since as early as the 1920s in refugee camps, conflict zones and inner city sites as 'an innovative, low-cost and effective method to contribute significantly to health, education, development and peace while addressing a litany of social and economic challenges'. (Inter-Agency Task Force on SDP 2003, 24) This notion of sport's intrinsic qualities, its ability to connect people and to build their capacities has become so popular within the Western culture that organizations with sport as the focal point of interventions began appearing globally under the banner of 'Sport for Development and Peace'. In recent years, SDP has increasingly been mobilized and integrated within the burgeoning nexus of international organizations and discourses that legitimize and encourage various interventions in the 'best interests' of and for the 'protection' of the world's most vulnerable people. The proverbial ball was rolling, nations and policy-makers were on board, but were the local populations? Did they have a choice? Were these questions being asked?

Where the groundswell of support could be commendable, the field of SDP is one rich in policy analysis, but poor in its documentation of how target participants actually culturally live, socially experience and personally feel, interpret and engage with the SDP experience. After reviewing the extant SDP literature, it is clear that the global collective of academics, policy workers and practitioners has come a tremendous way in the sophistication, diversity and critical analysis of empirical knowledge in this burgeoning field of study. Issues researched range amongst, but are not limited to, the functional nature of sport (Coalter 2009); SDP's ability to be an 'innovative' response to the failures of traditional socio-economic and cultural development processes (Levermore and Beacom 2009); sport as a transformative dimension of popular culture (Gasser and Levinsen 2004); sport's potential for bridging social divides and reconciling long-term cultural differences between people (Giulianotti 2011); facilitating universal alternatives for international development (Inter-Agency Task Force on SDP 2003); the ongoing recognition of the Global South as an expansive site of the North's 'development imagination' (Darnell 2012); and sport's potential for politically, culturally and geographically reshaping cities and landscapes through major games and sports mega-events (Wilson 2012). This eclectic grouping of research, it is argued, becomes evidence of the ostensible culturally transcendent qualities of sport and its ubiquitous function as a 'tool' or site of human development. Yet what is clear from this review is that the body, as sport's principal site of development and social transformation, is ironically an afterthought of the SDP scholarly community. With research being largely sociologically mute to 
deeper understandings of participants, much of our current academic understandings are the product of formal interviewing, short-term observations, programme evaluations and quantitative data analysis supplemented with theoretical applications that seem to disregard or temper the voices of those truly worth listening to: the participants themselves.

Extrapolating from this lack of corporeal investigation, there is an absence of comprehensive studies relating to the impact of SDP grassroots practices in relations of power amongst individuals, communities and the state. Moreover, very little attention has been paid to the everyday discourses within which specific SDP programmes are presented as the solution to inadequate education and health systems, social inequality, poverty and unemployment, under-development and democratization. Thus, to ignore both the body and the everyday life of SDP, participants would be to add to the growing body of SDP research that is replete with sweeping generalizations, optimistic statements, vague cautions and generic recommendations often misinterpreted by policy advocates, practitioners and the public (Coalter 2013). In this vein, we examine what researchers both in SDP (Darnell 2012; Giulianotti 2010; $\square$ Kay 2009; $\square$ Levermore 2011) and development more broadly (Fisher 2007; Weisgrau 1997) have identified as a central yet under-examined issue: the complexities and contradictions of how development is navigated, interpreted and perceived. This paper identifies a way forward through a morally guided and emphatic PSIR approach.

\section{Introducing PSIR}

PSIR is a form of participatory research that centralizes, prioritizes and situates sporting interventions and development through the experiences and daily lives of participants. PSIR seeks not to change behaviour or practice but aims to gain deeper insights and understandings of local populations, culture and experiences through and beyond the participation of SDP. Born from the challenges faced by the authors whilst conducting research with non-governmental organizations (NGOs), PSIR is focused on gaining greater understandings of cultural systems and social complexities through active roles as researchers from within the fieldwork setting. PSIR's methodological focus is on the establishment of a role that yields active membership and identity 'within' the specific SDP context. As anthropologists we are attuned to the ethics, functions and methodological norms of ethnographic research. Some may challenge the need for a newly constructed research methodology that incorporates ethnography for the purpose of examining SDP. Is the notion of development and the practice of sport the only new addition? And therefore, is PSIR superfluous to the traditional and established methodologies associated with qualitative social science research? We believe that PSIR should be considered as a needed methodological tool within the SDP sector according to the following rationale:

Firstly, despite ethnography being an established methodology within the social sciences, SDP has rarely been its subject; nor has it extended attention to the execution of effective immersion within specific spaces, activities and local populations. Greater attention has been devoted to the managerial cornerstones of policy, funding, partnerships and programming. Very rarely has such investigation situated findings according to participant experience and their social-economic development. Limited time in the field, formal data collection and passive observations has all diluted the potential for specific rich contextual insights. There is a clear methodological gap - despite commendable case study research (Forde 2013; Nicholls 2009; Sugden 2006) - within the field of SDP. There is a need for a methodology that combines ethnography, active intervention participation and social engagement outside of development and sporting spaces. A fresh approach to both SDP research and conducting ethnography can provide direction and reflection for this rapidly developing sector.

Secondly, PSIR rejects the notion of arriving in the field with an objective to create change or take action. Both authors acknowledge the merits of AQ3 'Participant Action Research' (PAR), an increasingly encouraged and implemented research technique (see Hayhurst et al., 2015), but consider this methodology ethically and strategically challenging. The role of 'expert' - according to PSIR - creates social boundaries, carries expectations and feeds into neoliberal and often complex historical and post-conflict baggage, thus reducing the capacity of the researcher to organically integrate and build authentic relationships with participants and those around them. Participation, integration and exchange are all built around a commitment to earn trust and identity by presenting oneself as a neutral. Change in the case of PSIR is an unintended consequence of the process.

Thirdly, and most critically, PSIR prioritizes the everyday lives and experience of the participants. Despite the inevitable variety of access, engagement and awareness of the development processes, management structures, organizations and deliverers, PSIR always situates this knowledge according to the recipients. From the lens of the SDP recipients, PSIR gains greater understandings of cultural systems and social complexities through embodied roles in the cultural groups under study. From such embodied carnal practices, PSIR eschews the bystander perspective to grasp action-inthe-making, not action-already-accomplished. Much like Wacquant's carnal sociology, 'it aims to detect and document the deployment of the practical schemata that fashion practice: the cognitive, conative, and affective building blocks of habitus, whose layering and operations are fully open to empirical investigation' $(2015,5)$. Such mirroring - physically, emotionally and socially - permits comprehension from the lens of the recipient: reciprocal social conceptions that are necessary for understanding individual strategies as well as recipient's interactions with SDP projects (Olivier de Sardan, 2005). 
Canadian male researcher into a member of a cycling team in Rwanda. Adopting a role 'within' allowed for opportunities to engage in the absence of social boundaries created by gender, race and status. The PSIR methodology extends traditional anthropology by not only living amongst and learning from others in unfamiliar cultures but by becoming active members of the micro-society formed by SDP. From both sides of the African continent, the authors uncover the complexities of navigating and conducting research within developing post-conflict locations, communities and cultures as diverse as the participants themselves. From the banana stands of rural Rwanda to the football pitches of Monrovia, an unpacking of an alternative research approach currently missing within the SDP literature is given.

\section{No longer playing the clown}

Anthropologists have traditionally adopted the role of novice, layperson or inquisitive outsider; observing, learning and practicing the local tasks of daily life in unfamiliar settings (Hammersley and Atkinson 2007, 79). Lofland (2006) coined the phrase 'acceptable incompetent', but also considered the advantages of researchers demonstrating or offering a skill in order to make interactions mutually valuable: 'There are settings and situations in which it is useful instead to highlight selected personal credentials or competencies in order to be deemed more worthy of informants time and attention or access various kinds of data' (70). The notion of applying one's skills in-the-field as a strategy to establish perspective, purpose and position, whilst creating a balanced exchange through shared interests is the central act of PSIR. PSIR is a physical and literal understanding of research 'with' participants instead of 'on' them.

An important distinction needs to be made in this analysis of participatory methodology, as much attention in recent years has been given to PAR and the quest to learn whilst educating and creating change. Participation within a philosophical anthropology has little intention to 'change people lives' and lies in contrast to Kurt Lewin's statement that 'The best way to understand something is to try to change it' (Greenwood and Levin 1998, 19). In actuality, our PSIR methodology, although organic and in many ways unintentionally adopted by both authors, broadens the social boundaries of engagement, allows for culturally accurate observations, minimizes power divisions and operates in multiple settings that extend beyond the formal operational structures of SDP.

In Liberia I needed to escape my western identity, I was frustrated being the silent observer and the restrictions of limited NGO activity. I needed a role, something to give me a name and help me integrate with those who I lived amongst. My primary gatekeeper was the captain of the local division three football team who trained every afternoon at the youth centre in the same district where I lived. I started to attend the training sessions as an observer and soon the coach began to engage with me about skills, drills and tactics. This evolved to a regular coaching position, a role where I lived, and an identity beyond the superficial. Over four years I maintained this position and followed a group of 20 post-conflict Liberian 'youths' as they navigated their way through complex social systems, status defined relationships, boundaries, desires, and their everyday norms. Their voices and experiences were my lens in which to understand the Liberian post-conflict culture, the role and impact of football to their identities and the effect of SDP. (Analysis of Liberian fieldwork methodology)

Our PSIR framework allows for methodological freedom whilst in-the-field, rather than arriving to-the-field with an official title and role that establishes boundaries and power imbalances from the outset. Hammersley and Atkinson (2007) claim that 'Expertise and knowledge may also be of value in the field as a basis for establishing reciprocity with participants' (69). PSIR allows for researchers to find their place, role and position within a participant group through measured inquisitive wanderings, observations and experiences rather than pointed, positivist inquiries. This gentle approach helps a researcher settle into and establish her or himself within new spaces from which observations within relevant settings can begin. A PSIR draws its strength from an understanding that from within the mundaneness of everyday life come rich nuanced understandings of culture and community. This organic process strengthens the initial relationship-building phase as the control is with the participants; they decide whether to accept a fellow athlete or introduce a new coach into their SDP space, and as such the SDP personnel may also have the same decision to make. The skill or shared interest is the basis for social integration, skill-based and cultural exchange, and with time engagement beyond the participatory activity into the lived experience. The remainder of this paper describes the fieldwork and research process of PSIR as well as the challenges, benefits and potential outcomes and learning to be gained. We begin with situating the need for adapting fieldwork methods and the conception of PSIR as a consequence of the challenges and restrictions experienced with an exclusive researcher-NGO partnership.

\section{The road to PSIR}

There is - alas - no simple recipe for fieldwork. (Eriksen 2001, 26)

Creating a research and learning partnership with NGOs is a necessity in many instances when focusing attention on the SDP sector as they are at the forefront of participant and community engagement. Ideally, this partnership should be transparent with arrangements based on expectations, aims, logistics, ethical and safeguarding guidelines and the agreement of needs of the researcher versus the capacity and willingness of the organization to host 
an outsider. Both authors of this paper began their - separate and unrelated - ethnographic fieldwork in East and West Africa with partnerships agreed with different SDP organizations, both researchers maintained this relationship for a number of weeks, and both made the decision over time to break away from this partnership to pursue what they considered more effective, more insightful, more valuable and more authentic data collection approaches. The decision was made to develop our positions from outsiders to active participants, enabling us to operate in many other everyday official, social, informal, private and traditional activities and spaces.

When examining SDP, NGOs are often the preferred research site for academics. Although SDP also operates elsewhere, NGOs are considered as an ideal in-the-field institution placed conveniently between the familiar SDP rhetoric and practice and the point of access to local populations. International and locally managed SDP NGOs provide a sense of familiarity whilst residing in culturally diverse environments (Levermore and Beacom 2009). We advocate for a sustained in-the-field presence, as Eriksen (2001) advises: 'Ideally, one should stay in the field long enough to be able to see the world as the locals see it' (27). Long-term fieldwork is the ideal- but not the imperative - research scenario for PSIR. Working with NGOs can have its limitations, restrictions and strategic components that may disrupt and influence the research process, levels of engagement and data. Such challenges were the catalyst for PSIR.

\section{Restrictions and suspicions}

This change in approach was a consequence of the limitations placed on the authors to freely engage with participants, creating restrictions and physical and social boundaries that ultimately became untenable. Holloway (1997) describes gaining access to participants in qualitative research as 'a continuing process of ongoing inclusion and exclusion of informants and not a once-and-for-all procedure because the size of the sample is not always established from the beginning of a qualitative study but depends on the emerging concepts' (20). In one author's case, access from within the SDP NGO closed through the progressive abuse, suspicion of personal intent and discouragement of the research by initial gatekeepers.

They created a situation [for me] that became unbearable, treated with disrespect and disregard ... Something [my situation] will and must be changed as they have destroyed my time here in Rwanda ... crushed its very purpose (Fieldnotes, Rwanda).

In contrast, in Liberia the issue lay in the discrepancy between the rhetoric and SDP image that built the NGO's identity and the actual lack of activity and delivery on the ground. The research placement provided such limited observation and opportunity for SDP participation that alternatives were sought:

The ... Organisation spend $90 \%$ of its time dealing with the consequences of street children, youth crime and violence. I spend most of my time in prisons, orphanages and reunifying young people back to their families. SDP is supposed to be the intervention that tackles the problems that creates the consequences but due to the lack of infrastructure and capacity the NGO almost exclusively tends to the outcome and not the cause. There's no time for SDP, no equipment, no programme to follow, no experienced or qualified coaches, I volunteered as a coach but have become a youth/social worker. (Fieldnotes, Liberia)

The realities on the ground and the complexities of establishing functional and productive research relationships with NGOs are challenges that can affect the ability of a researcher to manoeuvre and focus. Although such scenarios can prove enlightening as to the capacity, conditions on the ground and the insecurities of those implementing SDP, this is also restrictive to a researcher. Aside from capacity, programming and suspicion, the authors also questioned the validity of their observations.

\section{Best practice?}

Through the behaviour and practices of NGOs the validity and authenticity of SDP practices were bought under question. Were we being shown projects that promoted best practice and being denied access to the challenges, realities and failures? In the 1950s, Erving Goffman's 'Dramaturgical Perspective in Social Interaction' distinguished behaviour in relation to front stage and backstage behaviours, this concept highlights the relationship between the roles individuals or organizations play at given moments to various audiences in order to demonstrate best practice or conceal reality (Goffman 1959). As researchers, we had to decipher the potential for staging and performance and judge the extent to which this would affect the research process, relationships with participants and ultimately the possibility of attaining manipulated data:

When UK funders came to visit the project the cars had fuel and were cleaned, everyone arrived to the office on time and schedules were presented to us for the week. I looked further down the schedule and saw in big bold lettering the arrangement of a football match using the players from a previous project and multiple football related events and visits. I've been here 5 weeks and this is the first football related event I will see, the first time I have been given a formal schedule, the first time I will travel by car and the first time everyone is not working to Liberian time. What else changes to serve the observations of outsiders? (Diary entry Liberia 2010) 
The PSIR methodology allows for active roles within and outside of NGO programmes; such roles enable movement between the backstage processes of NGO operations and the front stage performance of SDP in action. Whilst considering researching SDP as a vehicle to gain a better understanding of the concept of sport for social impact, we recognized the absence of cultural and broader social engagement within SDP research that was limited with NGO observations. Here, we refer back to the PSIR rationale. We recognized that our fieldwork needed to operate within the paradigm of multiple spaces, activities and populations. Our initial experiences with NGOs prevented or controlled the manner in which we could achieve this. Often NGO staff positioned us not as researchers, but as experts or evaluators who were present for the purpose of critiquing, improving or delivering their programmes. This immediately formalized our attendance and affected the level of engagement with participants which is the core principle of PSIR. As previously discussed, the ethos of PSIR is to situate any data, reflections and interpretations to the experiences and lives of the recipients, and we believe that it is through this diverse, multi-sited and cross-cutting ethnographic method that local voices and the recipients of SDP are brought to the forefront. It is the intention of PSIR to situate development and SDP through social interaction, shared participation and lived experiences; the overall intended consequence of this is empowerment. It is the understandings of empowerment to which we proceed.

\section{PSIR: empowerment through the everyday}

\section{'Luck is the residue of design' - Branch Ritchey, 1946}

The central methodological act of participation enables the later stages of reflection, interpretation and reporting, which we believe is significantly advanced through a PSIR approach. PSIR's ability to penetrate deeper, produce complex narratives through 'thick' ethnographic accounts (Geertz 1973 ) allows us as researchers to not only gain insight into 'the mundane, the typical, and occasionally extraordinary features of everyday life that a participant might not feel worth commenting on in an interview' (Caddick et al. 2015, 100), but also generate rich understandings of people's everyday lives. These narratives - an intimate familiarity of participant's life-worlds - are critical, as Shaffir (2012) explains:

To see how people make sense of the situations they encounter in their daily routines and how they deal with these situations on an ongoing basis. Thus, in contrast to those who send out questionnaires to people or run them through sets of experiments, the approach taken here concentrates on achieving in-depth familiarity with the life-worlds of the people being considered by venturing out into these life-worlds. This means talking to people about their experiences and activities, as well as observing their behaviour and inquiring into their meanings, concerns, and practices, and, wherever feasible, participating in those same situations ourselves. (Course Description: McMaster University)

The development of this methodological perspective was conceived, in part, with the recognition of Physical Cultural Studies (PCS) as an emerging field of inquiry with many meaningful resemblances (Atkinson 2011; Silk and Andrews 2011). Specifically, the systematic study of trans-contextual, trans-historical and generic aspects of the human condition that simultaneously draw from multiple disciplines such as sociology, anthropology and political science, demonstrate the fluidity and contextually complex nature of these endeavours. It is through empirical accounts of human movement, activity, sport, leisure, health and well-being interpreted by us as field researchers embedded within a culture - as an extension of the anthropological discipline to which we had been influenced, understood and admired - that we can begin to develop critical understandings of participants life-world's. PCS theorization further pushed our thinking about seeking-out person-first, radically empathic, forward-thinking research projects by suggesting the embodiment and experience of those we seek to study offers further insight into the particular and the mundane of our subjects. Drawing from the critical reflections and offerings of Thin (2014), Frank (2010), and Wilkinson(2004), Atkinson's theorization encourages a project that sees human suffering and the possibility of human pleasure through movement; this notion is essentially the study of social life manifesting into and engaging with the existence of better worlds:

Riding with the boys up into the hills you can really get a good sense of the pride and love the country has for them. Each passing town the riders receive hoots and hollar's, people yelling their names and cheering them on. You can tell when they are passing through their own towns b/c you hear their names yelled loud and the celebrated rider will often move to the front or sprint through the city centre. They are two-wheeled gods. We begin to climb. They pedal easy, together, a true family, joking, chatting, passing bananas, slurping water and shooting the breeze. I climb feeling as if I was headed to Everest, each passing breath more difficult than the next. These roads have been well travelled by the riders. They know where to be careful on the descents, what angles are best for spotting trucks barrelling at them. They know where rocks are prevalent and when the winds will make one suffer. I had buried myself with a group of 8 to do some pace line work and prove myself. Once at the base of the hill, my weight and lack of recovery was too much for my legs and I dropped back as the youthful riders just sprang up and went for it Ronald (pseudonym), an amazing climber, saw this happen, my slouched body over my handlebars, the sweat pouring from my open pours and decided to help, lending me his wheel as I tried to catch my breath at altitude. I had 'burned all my matches' just to stay on his wheel until a bunch of other smiling riders came behind us and took us back to the main pack. 'Good job Musungu [white man], good job.' (Fieldnotes, Rwanda)

By participating and engaging in such a manner, in pushing beyond, pushing into 'deep investigation', we found ourselves back to the essence of 
anthropological ethnography and its evolution beyond simply shared knowledge; rather, it was about the practices and experiences of everyday life, the ways those practices are built out of shared knowledge, shared embodied experiences, plus all the other things that are relevant to the moment(Maanen 1988). As such, it's important to distinguish between ethnography and simply borrowing ethnographic techniques (Agar 1996). Ethnography requires a researcher to transgress theoretical and disciplinary boundaries whilst actively deciding to speak in truth, to make suggestions, to be morally grounded and attempt to rekindle a sort of positivism in research often described as non-value neutral, biased or unscientific (Game and Metcalfe 1996). This was no small task for early career academics whose formative years have been concerned with techniques, 'standards' or frameworks; deliberations that would create a form of what we describe as analysis paralysis, disabling researchers from behaving naturally and as comfortable as possible within the field.

In ‘Ten Lies of Ethnography', Fine (1993) boldly sets forth a set of important concerns, a set of realities that are part of the PSIR methodology by which we prepare a reality for a 'transformed presentation'. In dismembering ethnography in this way, Fine does well in reducing anxieties of ethnographic performance by making clear that idealism is likely a luxury in a pressured fieldwork circumstance and it is the researcher's ability to navigate this web of demands that will dictate the amount of deviation from formal and idealistic rules:

Ethnography is ultimately about transformation. We take idiosyncratic behaviours, events with numerous causes, which may - God forbid! - be random (or at least inexplicable to us mortals), and we package them. We contextualize events in a social system, within a web of meaning, and provide a nameable causation. We transform them into meaningful patterns, and in so doing we exclude other patterns, meanings, or causes. Transformation is about hiding, about magic, about change. This is the task that we face and is the reality that we must embrace. (290)

Through this embracing of methodological flexibility and the acknowledgement of potential trials and challenges, we both advocated for an approach that freed ourselves from too strict adherence to customary traditional standards of doing ethnography. We as field researchers have allowed ourselves the possibility of creating something well suited for our particular settings, styles and circumstances in the form of PSIR. In considering a series of methodological approaches, we challenged existent thinking about the role, purpose and dominant understandings of SDP whilst staying true to methodological sensibilities encapsulated within an anthropological ethnography. It is this balance between intense, empathic involvement with subjects and cognitive, emotional detachment from them required to conceptualize themes, patterns and structures or, generic social processes, and the organization of everyday life that this paper seeks to stress. In recognizing methodological limitations, opportunities and approaches, with some skill (and courage) a researcher is able to blend substantive and theoretical understandings into a methodological framework for the field. In one author's case, becoming a member of a cycling team, riding, sleeping, suffering, stretching, eating, cleaning and living alongside them, enabled the access required for observations surrounding, within and beyond the participation of SDP. This method of PSIR as an athlete whilst ensuring academic transparency increased data collection capacity in a fair and representative manner; without this level of methodological commitment their voices would hold less significance and upon reflection questionable validity.

In Liberia, taking on the role of a community football team coach placed the researcher between the formal levels of SDP participation and the SDP facilitators and stakeholders. Access was therefore gained within the spaces of planning, donor relations, implementation, delivery and programming. In this regard, the opportunity to conceal via backstage interactions became limited as the researcher became part of the off-the-field processes.

Meanwhile, occupying the status and identity of coach became a 'rite of passage' into the community setting, residents addressed me fondly and engaged with me during times away from training. By living amongst the football players within the community, opportunities developed to become more and more established socially, domestically and at times formally. By participating in the expected daily chores and norms of daily life as a young woman, acceptance was gained from neighbours as they watched on. Race and the position as a coach enabled access to 'adult' social spaces and events, whilst age and investment in youth footballers enabled access into youth social spaces and pursuits off the field. The PSIR methodology allowed for reflection and interpretation within multiple status defined groups and between the worlds of both formal and informal community interactions.

By doing so, both authors navigated the temporal and contextual issues of immersion in their everyday lives through a deep degree of empathy and inter-subjectivity that permitted them the confidence to 'write an account of the culture that accurately represents its core values, structures, processes and participants' (Atkinson 2012, 26). In this manner what we are proposing is a straightforward epistemology, with its direction purposely unclear, flexible and identified by in-the-field navigation. Investment and commitment to participants through a shared skill and interest significantly advanced the scope for integration and observation, facilitated the capacity for both researchers to decipher between the voice, actions, feelings, emotions and culture beyond the formal windows of activity during SDP participation.

\section{Empowerment through reflection and interpretation}

Waking up every day in rural Rwandan villages for the remainder of fieldwork, one author began rebuilding his depth of understanding through the interpretive process that shapes and guides human behaviour (Wax 1971, 3). Evans-Pritchard (1974) describes that 'to understand a people's thought 
one has to be able to think in their symbols'. As such an ethnographer must collect data from 'within the mediums, symbols, and experiential worlds that have meanings to [their] respondents' (79). As a first step in symbolic understanding, both researchers sustained close contact with their participants themselves, their families, neighbours, community officials, local shopkeepers and other actors whom formed the network of social and formal mapping. Often they would cook with participants' mothers and grandmothers, plant potatoes and pick mint with their brothers and sisters, go to the market and barter for vegetables with house workers, drink beers with community officials at the bar, and/or make popcorn in the village square for the after work commuters. For one author, learning local customs from tea preparation to the intimate relationship between Rwandans, their cows and the land provided significant cultural insight. This was later substantiated by academic research and internalized as a complex web of cultural understandings through the embodied experience. These lived experiences from within these communities became the central act of the learning, interpreting and reflection process. 'I wasn't simply observing, I was living'. (Fieldnotes, Rwanda)

In developing a PSIR framework that provided multiple entry-points of ethnographic enquiry, we allowed for richer understanding of the contrasting standpoints of participants lives to be made available to us. Our approach empowered participants to 'lead' the research, which with time provided an infinitely closer lived experience than previous understandings of the participants' life narratives during the initial period within the NGOs' shadows. From within the homes, streets and communities of participants, the authors could now manoeuvre with a sense of confidence, a feeling of acceptance and an established identity. The status as a friend, researcher and coach/rider within both the local community and participants' inner circles represented a comprehensive consideration of SDP processes and effects, cultural norms, social navigation, thoughts, feelings, modes of speech, belief systems and importantly in the context of SDP - a deeper understanding of the initial assumed societal challenges versus the needs and ambitions of the participants. Through a PSIR methodology, one can attempt to deconstruct, unpack, contextualize and frame the sociocultural conditions on the ground and trace the relevance and impact of an SDP intervention over significant time with reflection and interpretation driven by participant voices.

\section{Empowerment through ethnography}

The 'writing up' of field research has sought to create powerful insights, through narrative life histories, into the lived experiences of others in a 'way that can inform, awaken, and disturb readers by illustrating their [the readers'] involvement in social processes about which they may not be consciously aware' (Bochner and Ellis 2002, 221). In writing ethnography, the world you enter into, as a reader, is not a direct experience of 'East African cycling culture' or 'West African Football' per se; rather, readers are engaged in the interpretation of the society-as-reconstructed. And that reconstruction is coded or inscribed, whilst observations are transformed into descriptive text. Moreover, research does not - cannot - as Atkinson (1990) states, determine how readers will interpret others work: 'We read, and read into, the text, based on our own background knowledge and assumptions'. (2). The latter includes our competence as readers of sociological works amongst others. Readers bring to the work their knowledge and sympathy (or lack of it) for the ethnographic style of writing, as well as a host of barely articulated cultural capacities and prejudices. Ellis (1995) asks readers of research,

Did my story engender conversational response toward the text as you read? Did the story illustrate particular patterns and connections between events? Did you give the story to others to read because you think it speaks to their situation? ... What text did you, the reader create of my story? Did this narrative make you think about or shed light on events in your own life? ... Did the words I wrote elicit from you an emotional response to examine? What did you learn about yourself and your relationships through your responses to my text? (318-319)

Our role as anthropological ethnographers and storytellers is to evoke such questions from the data collected in a manner that conjures feelings of authenticity, believability and generalizability. As Coles (1989) describes, the beauty of a good story is its openness - how anyone reading it can take it in and use it for themselves; readers of our research (participants included) should judge this text ultimately in a self-referential manner, asking such selfish questions and using its knowledge. Yet, despite the belief in the PSIR methodology and the intended consequences of creating a balance of power between the researcher and the researched, whilst in the field one is often faced with insecurities and 'academic anxieties' derived by the method itself:

Outside of structuring travel schedules from the researcher's home community to the other rider's homes and villages, the author would prepare for the day with the understanding that it was necessary to do as the hosts instructed. Relinquishing this degree of ethnographic authority was initially uneasy, even as someone experienced in this cultural context. I was unaccustomed to the level of 'covertness' my study now required and became academically anxious when I felt I wasn’t productively gathering utilisable data. (Rwandan Journal)

Although an invented term, 'academic anxiety' is defined as the way in which young academics constantly question their manoeuvrings, intentions and perceptions of themselves in the field. If left unchecked, this can become paralysing to a field researcher, especially as she or he has a limited window of opportunity in which to collect and connect with those she or he seeks to study.

Researchers must recognize the counterproductive nature of such behaviour and take solace in collective features of fieldwork and PSIR. As such, an intended consequence of PSIR is a 'letting go' of the research process, allowing it to be driven by the local populations themselves through the lived 
and shared experiences of SDP. Although an often uncomfortable position for academics, this empowering of participants within the research process can result in a highly descriptive empowering ethnography, sensitive to cultural context but navigates between the formal western discourses and the operational and social processes on the ground through the voices and eyes of participants. In doing so, rich points are unearthed, discovered and can be addressed and discussed with participants in an open and honest way that contributes to the deconstruction of pre-defined understandings and concepts of everyday life through SDP participant perspectives.

\section{Deconstruction, conceptualization and empowering the 'local' through PSIR}

Despite the contribution by sociologists and other disciplines to gain further insights into diverse issues ${ }^{1}$ surrounding the operational processes of SDP from a western stakeholder perspective within developing countries, there is still a limited understanding of its interpretations by local populations, social impact of interventions and potential at behaviour change. Although valuable in their own rights, these research contributions make the organization, its policies and its approaches the centre of analysis, not its participants and communities. This uncritical presumption allows SDP evangelists ${ }^{2}-$ both within and outside of academia - to ignore fundamental questions of sports ability to do what it claims and bases a large amount of research on 'mythopic' understandings of sport's ability to cure any and all social ills (Coalter 2010).

A vast amount of early SDP literature (Kidd 2008; Richards 1997) relied heavily on assumption-based language (ie Sport is good!) to describe causes, people, participants and outcomes without critically considering participant perspectives, understandings and interpretations. The universal, illdefined and broad style rhetoric of SDP arguably masks reality when mobilized in various contexts. For example, on the African continent sport has largely been touted as a method to combat issues such as open discrimination, underdevelopment, ethnic violence, whilst in the same breath mobilized as a powerful vehicle for 'cementing fundamental social inequalities along 'racialised' lines' (Giulianotti 1999, 9). This dramatic contrast highlights the lack of awareness implementers of sport have of the importance of local populations' voices, and further demonstrates the need for an approach such as PSIR that considers research to be done 'with' participants as oppose to 'on' them 'to' them or 'for' them (Ristock and Pennell 1996).

We believe that academic enquiry has the opportunity - arguably a moral obligation - to deconstruct and contextualize the terminology of operational SDP into the specific workings of complex social and cultural systems. By critically engaging with these understandings through anthropologically sound fieldwork and methods, a humanistic approach to research in the first-person (Thin 2014) is established that allows researchers to engage in a (re)conceptualizing of SDP language from the perspective of the local, not simply recycling assumptions for the sake of academic exercise.

We are not suggesting researchers completely ignore organizational influence. Rather, PSIR recommends a focus on the participants' understandings, position and interactions with an SDP project, as they interpret it within the context of their everyday life. In doing so, researchers can then begin to deconstruct notions such as peace, youth, community and inclusion as a means of better situating contextually specific needs and understandings through the language of those being considered. Peace, for example, means different things to different people in different places. This process of unpacking such assumptions should lead to more valuable assessments of the role and outcome of SDP in location-specific contexts.

The methodological foundations of any PSIR research project must excel at deconstructing, conceptualizing and empowering local participants in capturing their understandings, experiences and relationships to broader terms, individuals and social contexts in which they are immersed. If not considered, the complexities, contradictions and problems with terms such as peace, sport, development and SDP-related work will inevitably be concealed (Wilson 2014). An honest, neutral and empirically based understanding is what PSIR seeks to attain through data and promote via ethnography.

\section{Discussion}

It adorns life, amplifies it and is to that extent a necessity both for the individual - as a life function- and for society by reason of the meaning it contains, its significance, its expressive value, its spiritual and social associations, in short, as a cultural function. (Huizinga 1950, 9)

Huizinga considered play as a socially constructed function 'in' culture; therefore, the study of play and games allowed important and unique insights into culturally specific practices, norms and ideals. In many ways, we follow the anthropological teachings of Huizinga with regard to the insights that play, games and physical activity can provide within local populations and specific groups in society. Herein lies the methodological perspective presented in this paper: SDP represents the coming together of play, games and sport to the development and human rights objectives of national governments, international working groups, the United Nations, those tasked with Corporate Social Responsibility (CSR) and sports federations. Active participation can take many forms, such as coach, athlete, spectator, official, teacher, volunteer, to name but a few, with the overall objective not to create change but to develop relationships, gain a deeper level of understanding and create the process of embedding oneself 'in' the space of SDP and everyday life.

Through PSIR, we as field researchers are allowed and forced into worlds of meaning and symbols that ultimately provide us with nuanced and rich 
descriptions of participants lived experiences from within, outside and around SDP. NGOs generally operate separate from and at times in opposition to those they are tasked to 'develop', a participatory approach is therefore a requirement to gain an anthropological perspective. The ambition of an anthropologist researching SDP in developing countries is to reflect, interpret, theorize and report through a narrative. In our opinion, the human face and participant voice of SDP has largely gone unrecognized due to a lack of time dedicated to the experiences of participant groups over a sustained period of time (Sparkes and Smith 2014). Becoming an active participator also allows for observations to go beyond the physical as the researcher shares the emotional responses and internalized feelings that can be discussed on a more personal level as someone who has shared an experience.

As researchers who endorse this methodological approach, we do not do so without caution. In recognizing the realities of academic everyday life, the gift of time is often difficult to acquire as research projects and funding can be limited and often dictate the length of time and resources dedicated to fieldwork. We were able to effectively integrate ourselves in differing roles due to our experience and skill sets in coaching and as athletes, expediting the insider-outsider period and making effective use of a participatory approach within a restricted time frame. Although we do not assume that all researchers with an interest in SDP or any other sporting discipline necessarily have these attributes, there are a number of roles that can be adopted without the need of a specific sporting skill, that is, a scorer or team assistant. Discovering a role that creates the transition from 'outside' to 'inside' and from 'passive' to 'active', is the initial methodological step.

When one becomes almost totally immersed in the lived experience of others and their norms become your norms, a potential for slippage can occur. A bias can be formed in favour of the viewpoints of those you interact with daily, or you lose your sense of self and that which usually drives your interpretations. In actively removing yourself from your everyday fieldwork environment, for brief moments, researchers are able to reflect and better understand, distinguish and fully engage in an unbiased manner. Only by stepping back can a researcher fully understand and absorb the data. Reflection in removed spaces during fieldwork becomes part of the PSIR methodology.

PSIR can be seen as a step towards empowering local populations in the research process, specifically by identifying and situating complex cultural environments through a lived experience and by emphasizing the importance of local voices. The numerous discussions between the authors of this paper would suggest that the realities and everyday norms of living in peace are very different when comparing contexts such as Liberia and Rwanda. Yet whilst notions of community shared similar traits, the contexts in which they found themselves were structured by drastically contrasting traditional rules and social hierarchies, making their interpretations and understanding of SDP in action uniquely different. The importance of understanding the needs of a society and population is surely the starting point of any research enquiry into SDP within a specific context. By gaining this level of local understanding, a researcher is able to fully engage with the policy, delivery, experience and evaluation of SDP programmes in a more descriptive and meaningful way to both local populations and stakeholders.

\section{Notes}

1.Such as volunteer experiences (Darnell 2007), the effectiveness of monitoring and evaluation within SDP NGOs (Levermore 2011), the [lack of] proper training or experience with vulnerable populations amongst volunteers (Kidd 2008; Levermore 2008; Richards 1997), the absence of local

AQ5 participant involvement in programming (Buetler, 2006Beutler, 2008; Coalter 2013), the potential perpetuation of harmful colonial relationships of inequality through SDP work (Darnell 2010; Hayhurst 2011) and the creation of unrealistic transformative outcomes in many of the

AQ6 poorest communities in the world (HobbermanHoberman, 2011).

2.A term coined by Professor Fred Coalter for those individuals who lack critical consideration of sports.

\section{References}

Agar, M. H. 1996. The Professional Stranger: An informal introduction to ethnography. 2nd ed. San Diego: Academic Press.

Atkinson, M. 1990. The Ethnographic Imagination: Textual Constructions of Reality. New York: Routledge.

Atkinson, M. 2011. “Physical Cultural Studies [Redux].” Sociology of Sport Journal 28: 135-144.

Atkinson, M. 2012. “The Empirical Strikes Back: Doing Realist Ethnography.” In Qualitative Research on Sport and Physical Culture, edited by K. Young and M. Atkinson, 23-50. Bingley: Emerald.

Bochner, A. P., and C. Ellis. 2002. Ethnographically Speaking: Autoethnography, Literature, and Aesthetics. Walnut Creek, CA: AltaMira Press.

Caddick, N., et al. 2015. 'Male Combat Veterans' Narratives of PTSD, Masculinity, and Health.” Sociology of Health \& Illness 37 (1): $97-111$.

AQ8 Choudry, A., and D. Kappor. 2013. NGOization: Complicity, Contradictions and Prospects. London: Zed Books. 
Coalter, F. 2009. “Sport-in-development: Accountability or development.” In Sport and International Development, edited by R. Levermore and A. AQ9 Beacom, 55-75. Basingstoke:Palgrave Macmillan.

Coalter, F. 2010. “The Politics of Sport-for-development: Limited Focus Programmes and Broad Gauge Problems?” International Review for the AQ10 Sociology of Sport 45 (3): 295-314.

Coalter, F. 2013. Sport for Development: What Game Are We Playing?. London: Routledge.

Coles, R. 1989. The Call of Stories: Teaching and the Moral Imagination. Houghton Mifflin.

Comstock, D. E., and R. Fox. 1993. "Participatory Research as Critical Theory: The North Bonneville, USA, Experience." In Voices of Change: Participatory Research in the United States and Canada, edited by P. Park, M. Brydon-Miller, B. Hall and T. Jackson, 103-124. London: Bergin AQ11 and Garvey.

Cutt, J. 1982. "Accountability, Efficiency, and the 'Bottom Line' in Non-profit Organizations.” Canadian Public Administration 25 (3): $311-331$.

\section{AQ12}

Darnell, S. 2007. 'Playing with Race: Right to Play and the Production of Whiteness in 'Development through Sport'." Sport in Society 10 (4): $560-579$.

Darnell, S. 2010. 'Power, Politics and 'Sport for Development and Peace': Investigating the Utility of Sport for International Development.” Sociology of Sport Journal 27: 54-75.

Darnell, S. 2012. Sport for Development and Peace: A Critical Sociology. London: Bloomsbury.

Ellis, C. 1995. Final Negotiations: A Story of Love, Loss and Chronic Illness. Philadelphia, PA: Temple University Press.

Eriksen, T. H. 2001. Small Places, Large Issues: An Introduction to Social and Cultural Anthropology (2nd ed). London: Pluto Press.

Evans-Pritchard, E. 1974. The Nuer: A Description of the Modes of Livelihood and Political Institutions of a Nilotic People. New York: Oxford University Press.

Fawcett, S. B., A. Paine-Andrews, V. T. Francisco, J. A. Schultz, K. P. Richter, R. K. Lewis, et al. 1996. 'Empowering Community Health Initiatives through Evaluation." In Empowerment Evaluation: Knowledge and Tools for Self-assessment and Accountability, edited by D. M. Fetterman, S. J. AQ13 AQ14 Kaftarian and A. Wandersman, 161-187. Thousand Oaks, CA: Sage.

Fine, G. A. 1993. “Ten Lies of Ethnography: Moral Dilemmas of Field Research.” Journal of Contemporary Ethnography 22 (3): $267-294$.

Fisher, W. F. 2007. 'Doing Good? The Politics and Antipolitics of NGO Practices.” Annual Review of Anthropology 26: $439-464$.

Forde, S. 2013. 'Fear and Loathing in Lesotho: An autoethnographic analysis of sport for development and peace." International Review for the AQ15 Sociology of Sport. Published “online first”. doi:10.1177/1012690213501916

Frank, A. 2010. Letting Stories Breathe. Chicago, IL: University of Chicago Press.

Frisby, W., C. Reid, S. Millar, and L. Hoaber. 2005. 'Putting 'Participatory' into Participatory Forms of Action Research.” Journal of Sport AQ16 Management 19:367-386.

AQ17 Game, A., and A. Metcalfe. 1996. Passionate Sociology. Sage.

Gasser, P., and A. Levinsen. 2004. 'Breaking Post-war Ice: Open Fun Football Schools in Bosnia and Herzegovina.” Sport in Society 7 (3): $457-472$.

Geertz, C. 1973. The Interpretation of Cultures. New York: Basic Books.

Giulianotti, R. 1999. “Sport and Social Development in Africa: Some Major Human Rights Issues.” The First International Conference on Sports and Human Rights, Sydney,

September 3 
Giulianotti, R. 2010. "The Sport for Development and Peace Sector: A Model of Four Social Policy Domains.” Journal of Social Policy 40 (4): 757-776.

Giulianotti, R. 2011. "Sport, Peacemaking and Conflict Resolution: A Contextual Analysis and Modelling of the Sport, Development and Peace Sector." Ethnic and Racial Studies 34 (2): 207-228.

Goffiman, E. 1959. The Presentation of Self in Everyday Life. London: Penguin Books.

Greenwood, D., and M. Levin. 1998. Introduction to Action Research: Social Research for Social Change. Thousand Oaks: Sage.

Hammersley, M., and P. Atkinson. 2007. Ethnography: Principles in Practice. 3rd ed. London: Routledge.

Hayhurst, L. 2011. 'Governing' the 'Girl Effect' through Sport, Gender and Development? Postcolonial Girlhoods, Constellations of Aid and Global Corporate Social Engagement. Toronto: Department of Exercise Sciences, University of Toronto.

Holloway, I. 1997. Basic Concepts for Qualitative Research. Oxford: Blackwell Science.

Huizinga, J. 1950. Homo Ludens: A Study of the Play Element in Culture. Boston, MA: The Beacon Press.

Inter-Agency Task Force on SDP. 2003. Sport for Development and Peace: Towards Achieving the Millenium Development Goals. New York: United Nations.

AQ18 Kay, T. 2009. 'Developing through Sport: Evidencing Sport Impacts on Young People.” Sport in Society 16 (1): 77-91.

Kidd, B. 2008. “A New Social Movement: Sport for Development and Peace.” Sport in Society 11 (4): 370-380.

Levermore, R. 2008. “Sport: A New Engine of Development?” Progress in Development Studies 8 (2): 183-190.

Levermore, R. 2011. 'Evaluating Sport-for-Development: Approaches and Critical Issues.” Progress in Development 11:339-353.

Levermore, R., and A. Beacom. 2009. Sport and International Development. New York: Palgrave Macmillan.

Lofland, J. 2006. Analyzing Social Settings: A Guide to Qualitative Observation and Analysis. 4th ed. Belmont, CA: Thomson Wadsworth.

AQ19 Maanen, J. V. 1988. Tales of the Field: On Writing Ethnography. Chicago: The University of Chicago Press.

Nicholls, S. 2009. “On the Backs of Peer Educators: Using Theory to Interrogate the Role of Young People in the Field of Sport-in-Development.” In Sport and International Development, edited by R. Evermore and A. Beacom, 156-175. Basingstoke: Palgrave Macmillan.

Richards, P. 1997. “Soccer and Violence in War Torn Africa. Soccer and Rehabilitation in Sierra Leone." In Entering the Field. New Perspectives in AQ20 World Football, edited by G. Armstrong and R. Giulianotti. Oxford: Berg.

Ristock, J. L., and J. Pennell. 1996. Community Research as Empowerment: Feminist Links, Postmodern Interruptions. Toronto, ON: Oxford University Press.

Shaffir. 2012. In (2014) Course Description (document title). McMaster University. https://sociology.momaster.ca/documents/undergraduate/courseoutlines/2014-2015/3o03_ws_fl4

Silk, M., and D. Andrews. 2011. “Towards a Physical Cultural Studies.” Sociology of Sport 28 (1): 4-35.

Sparkes, A. C., and B. Smith. 2014. Qualitative Research Methods in Sport, Exercise and Health: From Process to Product. London: Routledge.

Sugden, J. 2006. 'Teaching and Playing Sport for Conflict Resolution and Co-existence in Israel." International Review for the Sociology of Sport 41 (2): 221-240.

Thin, N. 2014. “Positive Sociology and Appreciative Empathy.” History and Prospects. Sociological Research Online 19: 5-32. 
Tsuda, T., M. Tapias, and X. Escandell. 2014. 'Locating the Global in Transnational Ethnography.” Journal of Contemporary Ethnography 43 (2): AQ21 123-147.

Wax, R. 1971. Doing Fieldwork: Warnings and Advice. University of Chicago Press.

AQ22 Weisgrau, M. 1997. Interpreting Development: Local Histories, Local Strategies. $\square$ Lanham, Md $\square:$ University Press of America.

AQ23 Wilkinson, I. 2004. Suffering: A Sociological Introduction.Oxford: Polity Press.

AQ24 Wilson, B. 2012. Sport \& Peace: A Sociological Perspective. Don Mills, Ont:OxfordUniversity Press.

Wilson, B. 2014. "Middle-walkers: Negotiating Middle Ground on the Shifting Terrain of Sport, Peace and Development." In Sport and Social Development, edited by K. Young and Chaiki Okada, 19-43. Bingley: Emerald. 